\title{
Exploring adaptation pathways in terms of flood risk management at a city scale - a case study for Shanghai city
}

\author{
Qian $\mathrm{Ke}^{1, \mathrm{a}}$, Marjolijn Haasnoot ${ }^{1,2,3}$, Marco Hoogvliet ${ }^{4}$ \\ ${ }^{1}$ Deltares, Boussinesqweg 1, 2629 HD, Delft, The Netherlands \\ ${ }^{2}$ Delft University of Technology, Faculty of Technology, Policy and Management, P.O. Box 5015, 2600 GA Delft, The Netherlands \\ ${ }^{3}$ Utrecht University, Department of Geosciences, P.O. Box 80115, 3508 TC Utrecht, The Netherlands \\ ${ }^{4}$ Deltares, Princetonlaan 6-8, 3584CB, Utrecht, The Netherlands
}

\begin{abstract}
Cities are vulnerable to flooding and historical events, for instance Hurricane Sandy in 2012, have showed that losses in the cities are costly. In the context of climate change and socio-economic development, future flood risk will inevitably rise; adaptive measures, for instance upgrading of sea dikes and floodwalls, improving drainage systems and implementing green infrastructures, are proposed under the changing environment in the cities. A question of when to implement what measures in the cities over time is then brought up. The approach of dynamic adaptive policy pathways is applied to formulate adaptation pathways for a case study of Shanghai to explore the optimal investment strategy in context of deep uncertainties. Adaptation concept is not only aiming to achieve optimal strategy but also to determine when to implement the measures. The adaptation pathways for three types of floods (coastal flood, river flood and pluvial flood) in Shanghai were formulated through a preliminary qualitative analysis. This could provide an insight to the long-term feasibility of adaptive flood risk strategies. This research could provide a rational indication for policy/decision makers on future adaptation strategy at the city scale.
\end{abstract}

\section{Introduction}

Urban flooding is a growing issue of concerning worldwide. Cities around the world are threatened by sea level rise as well as extreme river discharges and the intensified precipitation during a short period. These interactions potentially cause severe flood problems. In addition, cities are often densely populated and highly socio-economic developed centres with sophisticated networks of water-related infrastructures. Hence, the impact of flooding can be huge and costly. In addition to climate change and socio-economic growth, many cities are sinking as a result of land subsidence, for instance Jakarta, Ho Chi Minh City and Bangkok [1], which pose threats to the reliability of flood defence system and enlarge the potential inundation scale and depth. These complexity creates serious challenges for governments and planning- and water management authorities, that need to make decisions about long-term sustainable and climate proof investments [2]. For instance, which of the possible infrastructural investments with regard to flood risk management should be implemented, when climate change impact and socio-economic changes are uncertain? Is it urgent, or could investments be postponed? And can upcoming investments in urban planning, infrastructural maintenance renovation or replacement be used to reduce flood risk and increase

\footnotetext{
$\overline{{ }^{a} \text { Corresponding author: qian.ke@,deltares.nl }}$
}

resilience? These questions require careful consideration. The objective of this paper is to explore climate adaptation pathways for flood risk management at a city scale in context of such a dynamic environment and to examine the characteristics of the cities in the process of formulation of adaptation pathways in a long-term.

The outline of the paper will be organized as follows: Section 2 will describe the methodology of dynamic adaption policy pathways; Section 3 is a case study of Shanghai city; and discussion and conclusion will be followed in Section 4 and 5.

\section{Methodology}

Deltares uses Adaptive delta management to assess climate change impacts, develop adaptation measures and calculate the effectiveness, analyse the robustness and flexibility of the adaptation strategy and design water management plans.

The interdependence of the water system and economic system requires an integrated systems approach of the delta. The inherent uncertainties regarding the magnitude and rate of climate change and socioeconomic developments require an adaptive approach. The need to invest in expensive water related infrastructure on the short term requires an approach that supports decision making under uncertainty. Adaptive 
delta management combines these aspects. Figure $\mathbf{1}$ shows the dynamic approach of delta planning - dynamic adaptive policy pathways. It starts from the problem analysis and objective determination and followed by the identification of actions and the assessment of efficacy, used-by conditions and timing; and then to develop and evaluate adaptation pathways and to select preferred pathways. Subsequently, it needs to determine the contigency plan to keep the pathways on the right track and futher to specify a dynamic adaptive plan. Next, the plan needs to be implemented and also monitored in a couse of loop, which means the actions need to be reassessed if there is a need.

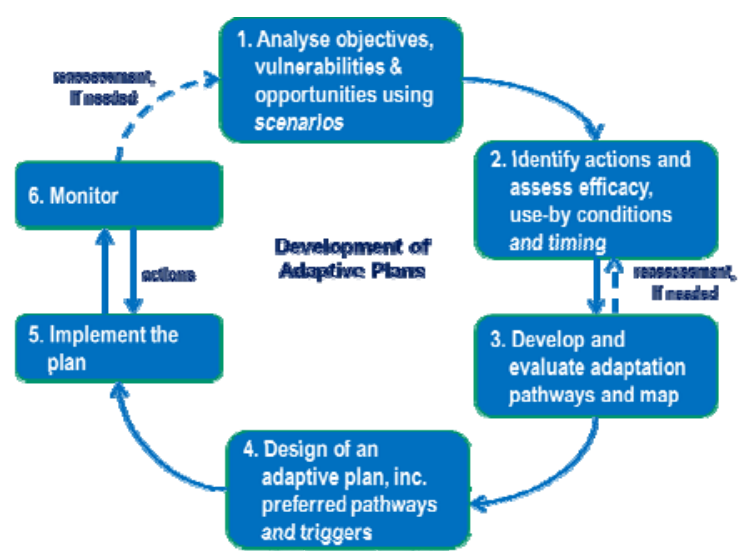

Figure 1 Approach of development of adaptive plans dynamic adaptive policy pathways (DAPP) [2]

\section{Case study: Shanghai city, China}

The approach of DAPP has been tested for the lower Rhine Delta in the Netherlands by [2]. In this paper, we're going to explore this approach in Shanghai as a tentative case by a quick scan. In recent years, several researches have highlighted that Shanghai is ranked as one of the most vulnerable cities worldwide in terms of current and future flood risk. Since Shanghai is experiencing a rapid growth with booming economy and dense population, the potential flood impact is expected to be far-reaching. The current flood risk is estimated at 70 million/year [3] and it will increase with a factor of 16 under the factors of sea level rise, land subsidence and socio-economic development until 2050 [4]. In the context of such a changing environment, pro-active adaptation measures are thus required to deal with future uncertainties.

At the end of 2013, Chinese government issued a "National Strategic Planning for Climate Change' [5], explicitly required developing climate adaptation strategies at a provincial level in China. In accordance with this appeal, Shanghai Development and Reform Commission and Shanghai Meteorological Bureau jointly formulated a project of 'Strategic Planning of Climate Adaptation for Shanghai' in June, 2015, which aims to recommend adaptation measures for various sectors and different areas in Shanghai. In addition, (local/international) insurance company also pays attention to the negative impacts of extreme events especially during the typhoon weather (strong wind, torrential rainfall and storm surge) on the areas of interested, such as the low-lying areas, the old-town of Shanghai, industrial area of Pudong District and the New Shanghai Disneyland, etc. Furthermore, according to the 'City Planning in Five Years (2016-2020)', Shanghai aims to become an influential international metropolis in the world till the year of 2020. Thus, a dynamic adaptive planning is crucial to reach this objective.

Based on these practical requirements, several climate adaptation measures, for instance the reinforcement of floodwalls and sea dikes, the construction of tide gates, the improvement of drainage systems and the construction of green infrastructures, have been discussed about its effectiveness by previous studies $[4,6]$. However, the solutions which are designed to address current problems will be probably no longer suitable in the future, which means a tipping point might be reached somewhere if no additional actions are taken. In order to extend the 'sell-by' date, therefore, how to formulate a dynamic adaptive long-term plan is a critical question for decision and policy makers of Shanghai city. An approach of DAPP is then proposed, which can analyse, design and monitor the adaptive actions in a loop for the system.

\subsection{Current situation and problem analysis}

Shanghai has been suffered from flood disasters for a long time due to its flat-low elevation and frequent typhoon weather. With climate change and socioeconomic growth, the frequency and intensity of flood events are expected to be increased and thus potentially cause high risk. In addition, Shanghai was ranked as top one city in term of flood vulnerability due to little resilience to a major flood and insufficient flood shelters for victims [7]. Facing with such a changing environment, (Chinese) National Climate Adaptation Programme required every major city to formulate climate adaptation measures and also to ensure the implementation. In terms of flood risk management, the aim of national programme can be implicitly translated into 'to protect major cities of China from flooding under climate change and to ensure the safety of property and residents'. In accordance with this, we define the 'success' of adaptive plan(s) as follows: 'the plan will be successful if no floods occur (in Shanghai) or even flood occurred only limited economic loss would be acceptable'. However, this objective is still vague to indicate the success of the plan. According to Taihu Basin Flood Prevention Programme the designed protection level for river flooding of Shanghai should maintain once in 1000 years [8] and Municipal Water Authority regulated that the designed protection level for drainage capacities in the downtown and new town of suburbs should be less than once in 5 years [9], which implies that the definition of 'success' could be more specific as 'the plan will be successful if the city can prevent once in 1000 years of flooding in the river and prevent once in 5 years of pluvial flooding for the urban area'. 


\subsubsection{Current system}

In this section, the flooding in the system was categorized into three types: coastal flooding, river flooding and pluvial flooding.

- Coastal flooding: the current coastal flooding is caused by storm surge during typhoon weather. The current protection level of sea dikes is between once in 200 years and once in 100 years.

- River flooding: four interrelated factors can increase water level in the Huangpu River: namely astronomic tide, storm surge, river runoff from Tai Lake and torrential rainfall accompanied with Typhoon (Figure 2). First, since the Huangpu River is a tide-dominated river, storm surge considerably influences the water levels in the downstream and middle stream. The coincidence of astronomic tide and storm surge could induce high storm tide; second, in order to release flood pressure for Tai Lake Basin, drainage water coming from Tai Lake due to torrential rainfall during Typhoon can increase river runoff in the Huangpu River, especially in the upstream; third, the urban drainage water during torrential rainfall is also considered as a potential flood driver in the Huangpu River. While these flood drivers contribute to different degrees to the high water levels in the Huangpu River.

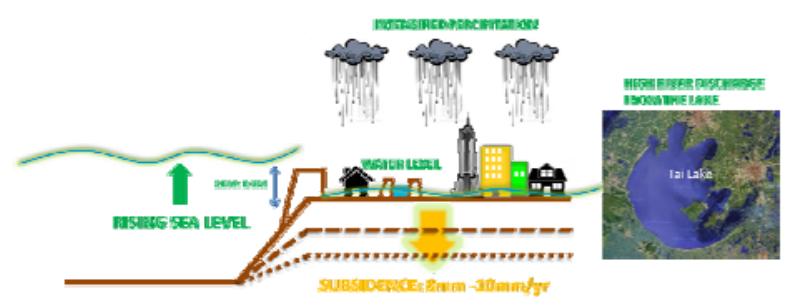

Figure 2 Problem overview under a changing environment in Shanghai

- Pluvial flooding: The torrential rainfall during typhoon or the rainstorm in a short period can increase the drainage burden in the sytem and if the drainage capacity cannot meet the requirements, pluvial flood easily occurs. Currently, in Shanghai, the drainage capacity is once in 1 year for most of the areas $(80 \%)$, for some locations are once in 3 years and once in 5 years $(20 \%)$.

\subsubsection{Future system}

Future socio-economic developments, sea level rise due to climate change and land subsidence, may require changes to the water management system. Due to climate change, the average sea level rise rate along East China Sea was estimated at $2.1 \mathrm{~mm} / \mathrm{yr}$ from 1991-2010, and the predicted rise rate between 2011-2030 and 2030-2050 would be $2.5 \mathrm{~mm} / \mathrm{yr}$ and $5 \mathrm{~mm} / \mathrm{yr}$, respectively [10][11]. Regarding land subsidence, it is reported that the compaction subsidence since 2011 is predicted as $6 \mathrm{~mm} / \mathrm{yr}$ along with $1 \mathrm{~mm} / \mathrm{yr}$ of tectonic subsidence. In general, the land subsidence is predicted as $8-9 \mathrm{~mm} / \mathrm{yr}$ in
Shanghai after 2010 [12]. Therefore, with such estimated increasing rate, the 'relative' sea level rise since 2011 is projected to be $21-23 \mathrm{~cm}$ by 2030 and $47-51 \mathrm{~cm}$ by 2050 , respectively.

Under the scenario of socio-economic development and sea level rise, the flood risk is estimated to increase 4 folds and 16 folds in the year of 2030 and 2050, respectively (see Figure 3).

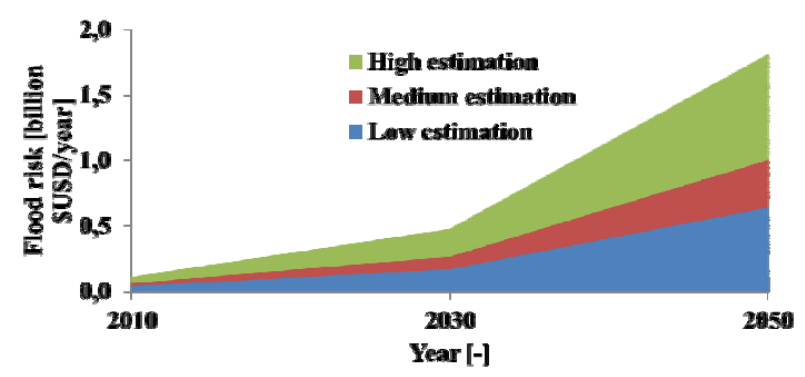

Figure 3 Potential flood risk under the combination scenarios of sea level rise and economic development in the year of 2010 , 2030 and 2050 [4]

\subsection{Determine actions}

As a result of the problem analysis, it is clear that flood risk will be increased in the future under climate change and socio-economic development. To ensure the safety from flooding in case of sea level rise, the increased river discharge and the increased precipitation, adaptive actions to prevent flooding need to be taken. Sea level rise, storm surge and high river discharge would increase water levels in the Huangpu River, the improvement of the floodwall (keep protection level of 1000 years return periods) can reduce the potential flood risk. In addition, the construction of storm surge barrier was regarded as an effective measure to prevent river flooding in the Huangpu River[4,13]. The flood control reservoir and flood detention basin in the upstream of the river could store extra water during the high discharge events or absorb extra water when the storm surge barrier is closed down. The flood diversion channel can alleviate water stress during high discharge events and storm surge events.

Coastal wetlands, such as mangroves, saltmarshes, lagoons and estuaries, play an important role in protecting human communities from storm surges, which can absorb and slow down the floodwater from storm surge.

Improvement of drainage capacity into 5 years of return period in the city can reduce the probability of inundation of pluvial flooding; the blue-green infrastructures, such as green roof, rain garden and bioswales provide extra space to collect and retain stormwater. In addition, some other actions, like porous pavements and the small-scale storage cellar in the community can play an important role in the prevention of pluvial flooding. 


\subsection{Assess efficacy, sell-by date of actions, and reassess vulnerabilities and opportunities}

Table 1 presents an assessment of the efficacy of each individual action and its sell-by date based upon expert judgement and previous preliminary analysis [4]. For determining the 'sell-by' date, we assume the linear change of climate, socio-economic development and land subsidence. For actions focusing on reduction of urban pluvial flood risk, no model results are available for Shanghai at this moment. Table 1 shows that the current plan is likely to be sufficient for achieving objectives for approximately another 5 years till 2020. After this point, there is a must of change. The improvement of other actions for the current system can enable the 'sell-by' date to be extended by approximately more than 50 years.

\begin{tabular}{|c|c|c|c|c|c|c|}
\hline \multirow{2}{*}{ Action } & \multicolumn{4}{|c|}{ Impact } & \multirow{2}{*}{$\begin{array}{c}\text { sell- } \\
\text { by } \\
\text { date }\end{array}$} & \multirow{2}{*}{ Cost } \\
\hline & Safety & Nature & Shipping & $\begin{array}{c}\text { Attractive } \\
\text { ness }\end{array}$ & & \\
\hline No actions & - & - & - & - & 2020 & 0 \\
\hline upgrade sea dikes & ++ & 0 & 0 & + & 2040 & +++ \\
\hline $\begin{array}{l}\text { storm surge } \\
\text { barrier }\end{array}$ & +++ & - & - & ++ & $\begin{array}{l}2070- \\
2080\end{array}$ & +++ \\
\hline wetlands & ++ & + & 0 & ++ & $\begin{array}{l}2040- \\
2050\end{array}$ & ++ \\
\hline $\begin{array}{l}\text { improvement of } \\
\text { floodwall }\end{array}$ & +++ & - & - & --- & $\begin{array}{l}2030- \\
2040\end{array}$ & +++ \\
\hline $\begin{array}{l}\text { flood diversion } \\
\text { channel }\end{array}$ & ++ & + & + & 0 & $\begin{array}{l}2060- \\
2070\end{array}$ & ++ \\
\hline $\begin{array}{l}\text { flood control } \\
\text { reservoirs }\end{array}$ & ++ & + & 0 & + & $\begin{array}{l}2060- \\
2070\end{array}$ & ++ \\
\hline $\begin{array}{l}\text { upgrade } \\
\text { drainage system }\end{array}$ & ++ & 0 & 0 & - & $\begin{array}{c}> \\
2100\end{array}$ & +++ \\
\hline $\begin{array}{l}\text { blue-green } \\
\text { infrastructure }\end{array}$ & + & ++ & 0 & + & $\begin{array}{l}2050- \\
2060\end{array}$ & + \\
\hline $\begin{array}{l}\text { small-scale } \\
\text { storage cellar }\end{array}$ & + & + & 0 & + & $\begin{array}{l}2030- \\
2040\end{array}$ & + \\
\hline
\end{tabular}

Table 1. Actions and assessment of their relative performance in terms of safety, sides effects on nature, shipping and attractiveness in Shanghai and 'sell-by' date of actions based on preliminary expert judgement on possible actions

These flood-risk actions can be divided into three categories corresponds to coastal flooding, river flooding and pluvial flooding. The construction of storm surge barrier at the mouth of Huangpu River intends to prevent extreme high storm surge (due to climate change) during the typhoon weather. This action has an effect on the improvement of floodwall. If the decision makers decide to ensure safety by the construction of storm surge barrier at the mouth of the Huangpu River, then the floodwall can be acted as an additional measure to prevent flooding. The flood control reservoir and flood detention area in the upstream of the river are to be function in case of high river discharge at the time of storm surge events (or the closure of storm surge barrier). The flood diversion channel can reduce flood risk in the future if the water level in the main river increases dramatically. In addition, the improvement of the sea dikes can deal with future sea level rise.

The action to address the urban flooding, for instance, the improvement of drainage system can be always an option for the decision makers as long as the budget is enough; hence this action is depending on the financial capacity of the city and other actions like green infrastructure and small-scale storage cellar can support as additional measures to reduce flood risk in the urban areas. While the action of green infrastructure could be more attractive since it can provide a nicer environment for the residents in addition to the function of flood control and it also serves effectively on flood risk reduction.

\subsection{Develop pathways}

The following figures shows three examples of adaptation pathways to address future climate change which leads to sea level rise, river discharge increment and precipitation intensification in the future of Shanghai. It also represents climate change will bring flood pressure from the sea, the river and the sky, respectively. Figure 4 shows adaptation pathways to prevent flood stress from the sea. In this map, starting from current situation, the objective will be missed in 2020. Following the black line of the current situation, it can be seen that three options that can be implemented after this point. If the upgrade of sea dikes is chosen, a tipping point is reached within about 20 years, a shift to a combination of either one of the other two actions will then be needed to reach the objective.

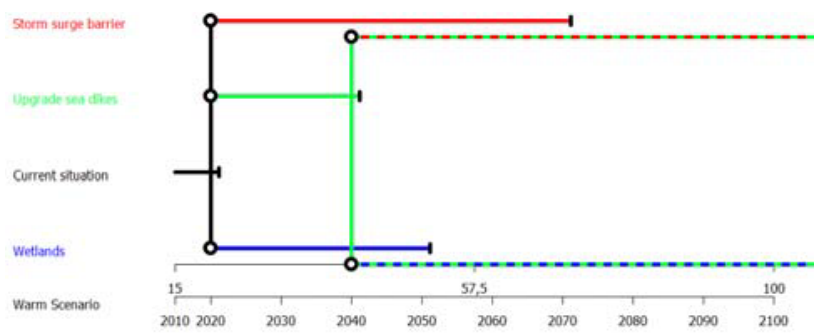

Figure 4 Example of adaptation pathways map to prevent flood stress from the sea

In Figure 5, starting from current situation, the objective cannot be reached after 2020. Followed by the grey line of current plan, three options are functioned to extend the 'sell-by' date. The tipping point is reached in 2040 if the action of 'upgrade floodwall' is chosen; a shift to a combination of either one of the other two actions will then be needed. But both of the combined actions (floodwall\& diversion channel and floodwall \& control reservoirs') will have a tipping point at 2070 and 2080, respectively. One choice of a combination of all three actions together after 2070 is chosen to reach the objective for the next 100 years.

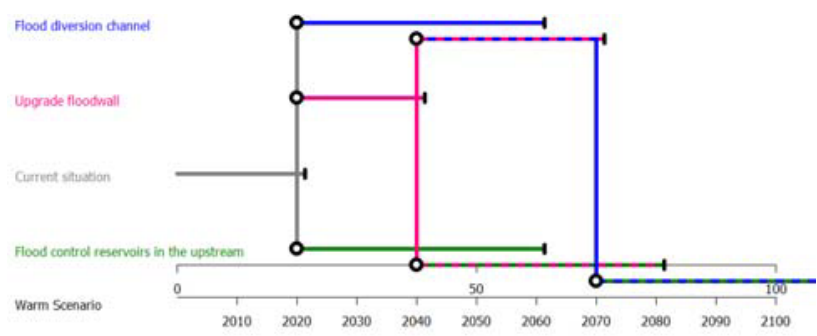

Figure 5 Example of adaptation pathways map to prevent flood threat from the river/lake 
In Figure 6, starting from current situation, the objective cannot be reached after 2015 . Followed by the grey line of current plan, three options are function to extend the 'sell-by' date. If an action of improvement of drainage system is first chosen, the tipping point will be reached in 2080 (or even more longer, which depends on the financial capacity), while with a combination of green infrastructures and the improvement of drainage system after 2060 the objective can be reached for the next 100 years. If the action of small-scale storage cellar or green infrastructure is first chosen, the tipping point can only be reached in 2040 or 2060; the shift to the other actions should be additionally implemented after this point; for instance, the combination of small-scale storage cellar, the combination of the implementation of green infrastructure and the improvement of drainage system can extend the sell-by date for the next 100 years.

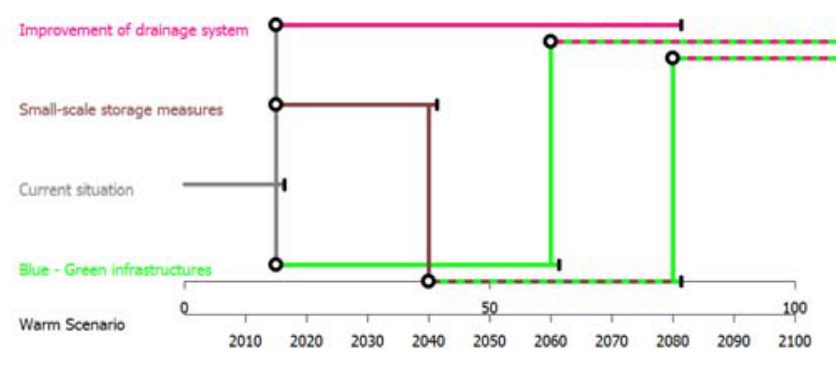

Figure 6 Example of adaptation pathways map to prevent flood threat from the sky (precipitation)

\subsection{Select preferred pathways}

This sub-section is focusing on the selection of the preferred pathways for the prevention of river flooding under climate change and socio-economic development in the long term. From the adaptation pathways map, preferred pathways can be selected. Different decision makers and stakeholders can have different preferred pathways, depending on their values and benefits. For Water Authority Agencies, a preference for the action is related to control the water levels during typhoon in the Huangpu River of Shanghai. For the environmentalist, they are focusing on the water quality and the preservation of environment. For the residents or the society, the influence of government is relatively less and the action will be more market-driven.

To select the pathway, it should be noted that all the actions aims to decrease water level in the Huangpu River either by preventing storm surge at the mouth of the river or by decease river discharge coming from the the upstream. Actions with long 'sell-by' dates are shown on the top or bottom of the map, while actions with short 'sell-by' dates are shown close to current plan. The next step is to add the 'sell-by' dates and the transfers to other actions that would extend the 'sell-by' date.

Figure 7 is an example of adaptation pathways under three perspectives.

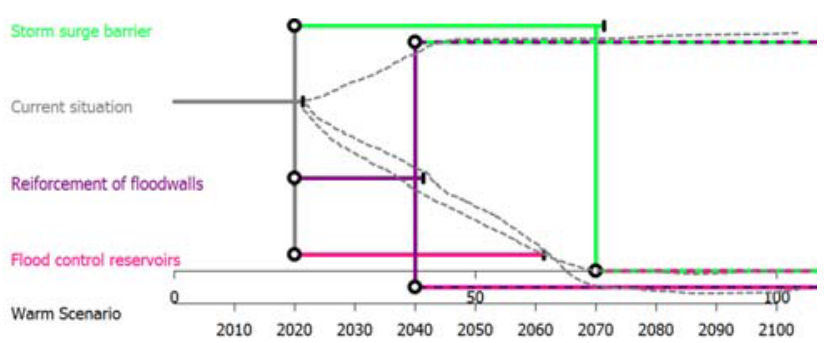

Figure 7 Adaptation pathways to address flood stresses of storm surge and high river discharge simultaneously due to climate change

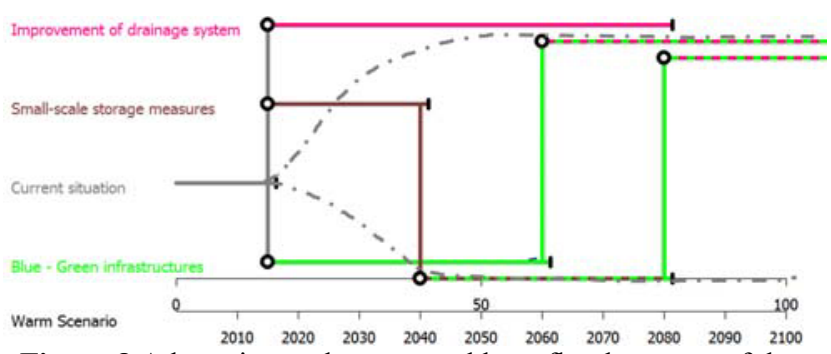

Figure 8 Adaptation pathways to address flood stresses of the intensified precipitation due to climate change and socio-economic development

There are two pathways we can select for pluvial flooding in Shanghai. One is the selection of the improvement of drainage system as soon as the 'sell-by' date is reached in current situation. The blue-green infrastructure can support in combined with this action afterwards. However, it should be noted that this pathway could be very costly; another pathway is to put the bluegreen infrastructure and small-scale storage measures in the first place and followed by the improvement of drainage systems. This one is more attractive and is also in line with the planning programme of the current Shanghai government.

\subsection{Determine contingency actions, signposts and triggers}

In order to keep the pathways on the track, contingency actions can be specified. For example, the spatial planning rules can support the construction of flood control reservoirs and flood detention basin in the upstream of the river. The contingency actions should be associated with a monitoring system and trigger values. The monitoring system specifies what to monitor, and the triggers specify when a contingency action should be activated. The determination of signposts and triggers could be further made by modelling.

\subsection{Specify a dynamic adaptive plan}

Based on previous steps of problems analysis, objectives formulation and pathways development, a dynamic adaptive plan can be specified. In order to reach and maintain the protection level of $1 / 1,000$ per year in Shanghai, the construction of storm surge barrier is quite necessary. The action of flood control reservoir should be implemented in case high river discharge increases water 
pressure when the storm surge barrier is closed. The combination of these two actions could be reserved into the mid-term planning (after 2050). Initial actions can focus on the improvement of floodwall (till the sell-by date of 2030). The actions of flood diversion channels can be served as the long-term actions while this action need support of spatial planning rules.

\subsection{Implementation of dynamic adaptive plan and monitoring}

As long the actions of the plan are implemented, and the Government continues monitoring sea level rise, land subsidence and climate changes. Further, the government monitors the changes in river discharge, water level in the river and the precipitation for the city.

\section{Discussion}

In this paper, we applied an approach to support decision making on long-term planning under uncertainties of climate change and socio-economic development, called Dynamic Adaptive Policy Pathways (DAPP). This approach assists in designing dynamic adaptive plans and we applied this approach at a city scale in order to examine the characteristics of the cities in the process of formulation of adaptation pathways in a long run. The 'dynamic' means the action can be reassesseed and continuously minitored after the implementation of the actions in a course of loop. For a city with a high-pace of socio-econmic development, it is quite necessary to conduct the assessment and reassessment of the actions to ensure the actions performs satisfactorily. In addtion, for a city, the design pattern can be very dynamic and the actions can change at any time to reach the specific goals. Thus our plans should be reassessed over time accordingly. The 'Adaptive' means the actions should reach a goal under a changing condition; the goal could be, for instance, to preserve the protection level of once in 1000 years for the Huangpu river. The actions should adapt the climte change and the socio-economic development over time.

\section{Conclusion}

The objective of this paper is to explore climate adaptation pathways for flood risk management at a city scale in context of a dynamic environment and to examine the characteristics of the city in the process of formulation of adaptation pathways in a long-term. The approach of Dynamic Adaptive Policy Pathways assists to result in adaptive plans that are able to deal with changing conditions for different types of flooding in a case study of Shanghai city. Frist, several adaptation pathways described the sequences of promising actions; and a monitoring system will relate actions to keep the plan on the track of a preferred pathway. These actions are anticipating to handle the vulnerabilities in the system over time and helps to reach the long-term goals. The combination of several actions was chosen to deal with future flood risk and was as the most promising pathway in the long-term plan. Second, the selection of preferred pathways under different perspectives can assist to frame the long-term plan from different ways. Third, the city application emphasized that apart from political uncertainties, the socio-economic development in a city was the main source of deep uncertainties in a time of exploring the adaptive pathways.

\section{References}

1. Waltham T. (2015), Sinking cities - An intergtrated approach towards solutions.

2. Haasnoot M., Kwakkel J. H., Walker W. E., and ter Maat J.(2013).Dynamic adaptive policy pathways: A method for crafting robust decisions for a deeply uncertain world. Glob. Environ. Chang., vol. 23, no. 2, pp. 485-498.

3. Hallegatte S., Green C., Nicholls R. J., and CorfeeMorlot J. (2013) Future flood losses in major coastal cities, Nature. Climate. Chang., vol. 3, no. 9, pp. 802-806.

4. Ke Q. (2014). Flood risk analysis for metropolitan areas - a case study for Shanghai, November. Delft Univeristy of Techonology

5. NDRC (2014). National Programs on Climate Adapatation. Report in Chinese

6. Qin H. P., Li Z. X., and Fu G. (2013).The effects of low impact development on urban flooding under different rainfall characteristics, Journel of Environment. Manage., vol. 129, pp. 577-585,

7. Balica S. F., Wright N. G., and van der Meulen F. (2012). A flood vulnerability index for coastal cities and its use in assessing climate change impacts, vol. 64, no. 1.

8. Ministry of Water Resource of China. (1998). Flood Prevention Programme for Tai Lake Basin. In Chinese

9. Minidtry of Housing and Urban-rural Development. (2014). Design code of outdoor wasterwater engineering. Report number: GB 50014-2014. In Chinese

10. Li Y., Qin Y. and Duan Z. (1998). An estimation and assessment of future sea level rise in Shanghai Region, Acta Geogr. Sin., vol. 5.

11. Yin J., Hu Z., Xu X., Wang S. (2011). Multiple scenario analyses forecasting the confounding impacts of sea level rise and tides from storm induced coastal flooding in the city of Shanghai, China. Encironmental Earth Sci, vol. 63, pp. 407414.

12. Gong Y. S. (2008). The impact of land subsidence in Shanghai. Yangtze River, vol. 39, no. 6, in Chinese

13. Cui Y. L. D., Zhao G. (2012). Preliminary analysis of storm surge barrier at the mouth of the Huangpu River. Adv. Sci. Technol. Water Resour., vol. 32, no. 1, pp. 1-4., in Chinese 